\title{
Intramuscular Injections for COVID-19 Vaccinations
}

Kathy S. Thomas

$\mathbf{I}$ deep into the muscle. Muscle tissue has a generous blood supply; thus, medications administered into muscle are rapidly absorbed into circulation. The flu vaccination, and more recently, the coronavirus disease 2019 (COVID-19) vaccination are examples of medications routinely administered by intramuscular injection into the deltoid muscle, the preferred intramuscular site $(1,2)$.

The following protocol specifically addresses the intramuscular administration for the 2 COVID-19 vaccines manufactured by Moderna and Pfizer-BioNTech.

\section{CLINICAL INDICATION}

- Moderna COVID-19 vaccine: authorized for use under an Emergency Use Authorization for active immunization to prevent COVID-19 caused by severe acute respiratory syndrome coronavirus 2 (SARSCoV-2) in individuals 18 y of age and older (3).

- Pfizer-BioNTech COVID-19 vaccine: authorized for use under an emergency use authorization for the prevention of COVID-19 caused by SARS-CoV-2 in individuals $16 \mathrm{y}$ of age and older (4).

\section{CONTRAINDICATIONS}

- Severe allergic reaction (e.g., anaphylaxis) after a previous dose of a messenger RNA COVID-19 vaccine or any of its components, including polyethylene glycol or polysorbate $(3,4)$.

\section{PATIENT PREPARATION/EDUCATION}

- Patient may eat and take medications as prescribed.

- Complete the Centers for Disease Control and Prevention's Prevaccination Checklist for COVID-19 Vaccines to determine whether the patient has any of the following conditions (5):

1. Current fever or feeling sick.

2. History of an allergic reaction to any component found in the COVID-19 vaccine.

3 . History of an allergic reaction to another vaccine or injectable medication.

4. History of a severe allergic reaction to food products, pets, environment, or oral medication.

5. Recent vaccine in the last $14 \mathrm{~d}$.

COPYRIGHT @ 2021 by the Society of Nuclear Medicine and Molecular Imaging. DOI: $10.2967 /$ jnmt.121.262049
6. Passive antibody therapy for the treatment of COVID-19.

7. Weakened immune system or currently taking immunosuppressive drugs or therapies.

8. Bleeding disorder.

9. Pregnancy or breastfeeding.

- Explain the injection procedure (preparation and location) and the need for postinjection monitoring for $15 \mathrm{~min}$ (patients with no known allergies) or $30 \mathrm{~min}$ (patients with known allergies) after vaccination. Note: after administration of the second dose of the vaccine, all patients should wait $30 \mathrm{~min}$.

- Provide the patient with the emergency use authorization fact sheet for recipients and caregivers for the respective vaccine being administered $(3,4)$.

PHARMACEUTICAL PREPARATION: PERFORMED IN A CLEAN AREA USING STRICT ASEPTIC TECHNIQUE AT ALL TIMES

- Perform appropriate hand hygiene.

- Bring vaccine to room temperature. Prepared vaccines must be stored between $2^{\circ} \mathrm{C}$ and $25^{\circ} \mathrm{C}\left(35^{\circ} \mathrm{F}\right.$ and $77^{\circ} \mathrm{F}$ ) and administered within $6 \mathrm{~h}$ of preparation.

1. Pfizer-BioNTech vaccine can be kept at room temperature for up to $2 \mathrm{~h}$ before reconstituting.

2. Moderna vaccine should be brought up to room temperature, which usually takes $1 \mathrm{~h}$. The vaccine can stay at room temperature for up to $12 \mathrm{~h}$ as long as the vial has not been punctured.

- Needle gauge is site-specific; needle length is patient-specific (Table 1).

Moderna Preparation (3)

- Verify expiration date on vaccine vial.

- Hold the vial upright and gently swirl the vaccine. Do not shake.

- Inspect the vial for discoloration; discard if discolored.

- Each 5-mL multidose vial contains 10 doses.

TABLE 1

Centers for Disease Control and Prevention's Vaccine Administration: Needle Gauge and Length-Deltoid Muscle (6)

\begin{tabular}{ll}
\hline \multicolumn{1}{c}{ Adults, $19 \mathrm{y}$ and older } & \multicolumn{1}{c}{$22-25 \mathrm{gauge}$} \\
\hline $130 \mathrm{lb}(60 \mathrm{~kg})$ or less & $1 \mathrm{in}(25 \mathrm{~mm})$ \\
$130-152 \mathrm{lb}(60-70 \mathrm{~kg})$ & 1 in $(25 \mathrm{~mm})$ \\
Men, $152-260 \mathrm{lb}(70-118 \mathrm{~kg})$ & $1-1.5 \mathrm{in}(25-38 \mathrm{~mm})$ \\
Women, $152-200 \mathrm{lb}(70-90 \mathrm{~kg})$ & $1-1.5 \mathrm{in}(25-38 \mathrm{~mm})$ \\
Men, $260 \mathrm{lb}(118 \mathrm{~kg})$ or more & $1.5 \mathrm{in}(38 \mathrm{~mm})$ \\
Women, $200 \mathrm{lb}(90 \mathrm{~kg})$ or more & $1.5 \mathrm{in}(38 \mathrm{~mm})$ \\
\hline
\end{tabular}


- Draw the recommended dose of $0.5 \mathrm{~mL}$ into a 3.0$\mathrm{mL}$ syringe using a $25 \mathrm{-g}$ needle or smaller.

- Record the date and time that the vial was first punctured.

\section{Pfizer-BioNTech Preparation (4)}

- Verify expiration date on the vaccine vial and diluents.

- Invert the vial 10 times before dilution. Do not shake.

- Inspect the vial for discoloration; discard if discolored.

- Dilute the vial contents using $1.8 \mathrm{~mL}$ of $0.9 \%$ sodium chloride, USP. Do not use bacteriostatic $0.9 \%$ sodium chloride or any other diluent. Do not add more than $1.8 \mathrm{~mL}$ of diluent.

- Invert the vial 10 times. Do not shake.

- Each 1.8-mL multidose vial contains 5-6 doses.

- Draw the recommended adult dose of $0.3 \mathrm{~mL}$ using a dead-volume syringe or needle (limits dead space; allows full volume to be administered).

- Record the date and time the vaccine was mixed in the vial.

\section{VACCINATION ADMINISTRATION}

- Always follow the "Rights of Medication Administration" when administering any medication (7):

1. Right patient.

2. Right vaccine and diluent (if applicable).

3. Right time (product expiration time/date).

4. Right dosage.

5. Right route (including needle gauge, length, and correct technique).

6. Right reason.

7. Right documentation.

- Perform proper hand hygiene and then don protective equipment, including face covering and clean gloves.

- Identify the injection site (center of the deltoid muscle approximately $5 \mathrm{~cm}$ [2 in] below the acromion process on the lateral side of the shoulder above the axillary fold [armpit]).

- Clean the injection site with a sterile alcohol wipe using a circular motion from the center to a circle of $5-7.5 \mathrm{~cm} \mathrm{(2-3} \mathrm{in).} \mathrm{Allow} \mathrm{alcohol} \mathrm{to} \mathrm{dry.}$
- Stabilize the patient's arm with the nondominant hand and insert the needle into the injection site at a $90^{\circ}$ angle and administer the entire dose. Note: do not aspirate the syringe before or after administering the injection.

- While injecting, use one hand to stabilize the barrel of the syringe and the other hand to push the plunger to administer the vaccine.

- After needle removal at the same $90^{\circ}$ angle, apply gentle pressure to the injection site with a clean gauze for several seconds, and then apply an adhesive bandage.

- Discharge the patient to the holding area for a 15 - to 30-min observation period.

\section{PRECAUTIONS}

Anaphylaxis has been reported after COVID-19 vaccine administration. Sites administering vaccinations should have a written protocol outlining appropriate medical treatment, including required personnel, equipment, and medications in the event of an acute anaphylactic reaction (8).

\section{REFERENCES}

1. Practical procedures: Injection technique 1 -administering drugs via the intramuscular route. Nursing Times website. https://www.nursingtimes.net/clinical-archive/ assessment-skills/injection-technique-1-administering-drugs-via-the-intramuscularroute-23-07-2018/. Accessed February 2, 2021.

2. What are intramuscular injections? Healthline website. https://www.healthline.com/ health/intramuscular-injection\#injection-sites. Accessed February 2, 2021.

3. Pfizer-BioNTech COVID-19 vaccine. CDC website. https://www.cdc.gov/vaccines/ covid-19/info-by-product/pfizer/. Accessed February 2, 2021.

4. Moderna COVID-19 vaccine. CDC website. https://www.cdc.gov/vaccines/covid19/info-by-product/moderna/. Accessed February 2, 2021.

5. Prevaccination checklist for COVID-19 vaccines. CDC website. https://www.cdc.gov/ vaccines/covid-19/downloads/pre-vaccination-screening-form.pdf. Accessed February 2, 2021.

6. You call the shots: vaccine administration-needle gauge and length. CDC website. https://www.cdc.gov/vaccines/hcp/admin/downloads/vaccine-administrationneedle-length.pdf. Accessed February 2, 2021.

7. Quality indicators for safe medication preparation and administration: a systematic review. National Center for Biotechnology Information website. https:// www.ncbi.nlm.nih.gov/pmc/articles/PMC4401721/. Accessed February 2, 2021.

8. Barnwell LH, Crosthwaite MH. COVID-19 vaccination: an overview and education tool for nuclear medicine technologists. J Nucl Med Technol. 2021;49: $7-10$. 